Orginal Article

\title{
Antibiotic use in Moshi Urban: A cross-sectional Study of Knowledge and Practices among Caretakers of Children in Kilimanjaro Tanzania
}

Benedicto J Petro ${ }^{1}$, Sixbert Isdory Mkumbaye ${ }^{1,2}$, Rukia Rajab Bakar ${ }^{1,3}$, Nassra Is-hak Yussuf $^{1,3}$, Pius G. Horumpende ${ }^{1}$, Akili Mawazo ${ }^{4}$, Debora Charles Kajeguka ${ }^{1^{*}}$

\footnotetext{
${ }^{1}$ Department of Microbiology and Immunology, Kilimanjaro Christian Medical University College, Moshi, Tanzania ${ }^{2}$ Department of Clinical Laboratory, Kilimanjaro Christian Medical Centre, Moshi, Tanzania

${ }^{3}$ Department of Nursing and Midwifery, The state University of Zanzibar, Zanzibar

${ }^{4}$ Department of Microbiology and Immunology, School of Medicine, Muhimbili University of Health and Allied Sciences, Dar es Salaam, Tanzania.
}

*Corresponding author: Debora Charles Kajeguka. Department of Microbiology and Immunology, Kilimanjaro Christian Medical University College, Moshi, Tanzania. Email: debora.kajeguka@kcmuco.ac.tz

\begin{abstract}
Introduction

Antibiotics are commonly accessed and used for the management of illness in children without a prescription. We investigated the caretaker's knowledge and practices on antibiotics and antibiotics use to their children.

\section{Method}

This was the hospital-based cross-sectional study conducted from April to July 2017 in three facilities located in Moshi Municipality. A convenience sampling was employed to select for caretakers with their sick children at KCMC, Mawenzi hospital, and Longuo dispensary. Face-to-face interviews were conducted with 224 caretakers who had visited health facilities with their children seeking health care.

\section{Results}

The majority (87.9\%, 197/224) of all interviewed caretakers had good knowledge of the use of antibiotics. Irrespective of knowing that it is not safe to self-medicate a child with any antibiotics $(95.1 \%, 213 / 224)$, most $(61.6 \%, 138 / 224)$ caretakers practiced selfmedication with the medicines. Having two children (aOR $=7.75,95 \%$ CI: $1.89-31.67)$ and having three children $(\mathrm{aOR}=7.23,95 \% \mathrm{CI}$ : 1.08-48.51) were significantly associated with good knowledge of antibiotics.

\section{Conclusion}

This study has revealed that caretakers in Moshi had a good knowledge of antibiotic use. However, despite such good knowledge, malpractices were observed. We call upon the use of media campaigns to advocate for the importance of the rational use of antibiotics and its effect on human health and the risk of antimicrobial resistance development. Rwanda J Med Health Sci 2021;4(3):347-356
\end{abstract}

Keywords: Antibiotic, Knowledge, Practices and Tanzania 


\section{Introduction}

The use of antibiotics to manage illnesses in children is a common practice among caretakers and is fueled by public knowledge, attitudes, and expectations.[1,2] Inappropriate use of antibiotics leads to antimicrobial resistance (AMR) which is the global public health problem [3] because it compromises the effectiveness of treatment of infectious diseases.[2] Several studies have indicated that children are given antibiotics to treat acute respiratory infections and diarrhea,[4-6] though, antibiotic treatment may not be required and it is unnecessarily prescribed in most cases.[6]

In 2001, the World Health Organization (WHO) documented recommendations for an improved and coordinated global effort to contain AMR .[7] The interventions are most likely to be successful if the following factors are understood in a given setting; 1) which infectious diseases are important, 2) which antibiotic/antimicrobials are commonly used and by whom, 3) and lastly, what factors determine the antibiotic/ antimicrobial use.[7] The WHO Global action on AMR plan recognizes the role of societies in causing AMR and emphasizes understanding the social and behavior of societies to support the achievement of the objectives set to tackle the AMR [8]. A study reported a list of possible causes of AMR as being the acts of inappropriate use of medicines which include failure to complete treatment, skipping of doses, re-use of leftover medicines, and overuse of antibiotics .[9] The major important cause is the lack of knowledge on antibiotics and antibiotic use that may collectively promote the selection and transmission of antibiotic-resistant bacterial strains.[10]

Different studies elsewhere have investigated parents/caretakers' knowledge of antibiotics, and they demonstrated poor knowledge regarding antibiotic use,[11-14] and its consequences, which led to inappropriate attitudes and practices.[14] Contributors to poor knowledge include parents/caretakers' low income, rural residence, and low education level.[13,15] Appropriate public knowledge and a positive attitude toward antibiotic use are significant factors in rational antibiotic use and in minimizing the development of AMR in the community.[16] Therefore, understanding the caretaker's knowledge and practice regarding antibiotic use in the management of childhood illnesses is important.
In Tanzania, several studies have been conducted to explore community understanding regarding antibiotic use.[10,17] The studies revealed that overall, communities have low levels of knowledge of the concepts of antibiotics and their use and the risk of AMR development. Moreover, wealthy participants with a higher level of education had a relatively higher level of knowledge.[17] Neither of these studies, however, assessed knowledge and practices regarding antibiotic use among caretakers/ parents who seek care and treatment. Hence, there is limited data on the caretaker's understanding of antibiotic use, its effect when used without a doctor's prescription, and AMR development. Given the recent upsurge in AMR worldwide and Tanzania in particular, it is essential to assess the caretaker's knowledge and practices of antibiotic use for their children in Moshi, Kilimanjaro.

\section{Methods}

\section{Study area and design}

This was the hospital-based cross-section study conducted from April to July 2017 in facilities located in Moshi Municipality. It involved caretakers visiting health facilities in the Pediatric, Out Patient Department, Antenatal clinic, and Reproductive Health Clinic (RHC) at Kilimanjaro Christian Medical Centre (KCMC), Mawenzi hospital, and Longuo dispensary.

\section{Sampling technique and population}

Convenience sampling, which is a technique by which a sample is taken from a group of people easy to reach and contact, was used in this study. In this study, eventually, all caretakers (parents/guardians) present at the health facility who were seeking care and treatment for their children during the time of data collection were recruited.

\section{Data collection}

A structured questionnaire was used as a tool to measure the caretakers' knowledge and assess practices. The questionnaire was developed based on previous studies[18,19] with few modifications and used in a pilot study that involved ten caretakers. After the pilot, adjustments in some statements were to make the questionnaire easy to understand and yet give accurate and credible data. Briefly, the questionnaires had three sections.

Section one: This section included the caretaker's sociodemographic data which covers the basic data such as age, sex, occupation, education level, residence, income per month, and the number of children. 
Section two: 12 questions provided information about the caretaker's knowledge of antibiotics. Briefly, the knowledge possessed by caretakers refers to their understanding of antibiotics including "Have you ever heard of this medication; ceftriaxone, penicillin, amoxicillin, and metronidazole?", If a child presents with cough, running nose, and a sore throat, would it cure more quickly if he/she receives an antibiotic?", "Do you know that inappropriate antibiotic use can cause the risk of antibiotic resistance?", "Antibiotics should only be obtained with a doctor's prescription?", "An antibiotic can be used for any child who presents with a fever? ", "are you aware that you should follow the instructions given by the doctors when giving antibiotics to your child?".

Section three: This section included information about practices and reasons for self-medicating a child without a doctor's prescription. The following questions or statements have been asked "Have you ever requested antibiotics from your doctor even if it was not included in the treatment for your child's illness?' "Would you reuse an antibiotic which you had used in the past if your child presents similar symptoms?", "do you consult a doctor if the symptoms are not relieved by selfmedication?", “ Do you Inform the pharmacist/ doctor if the child is already on other medication for some other illness?", "Is self-medication with any antibiotics is safe in children?", "Do you check the expiry date of medicines before giving to your children?", Are you aware of dose/frequency of dosing/duration of treatment?", " Lack of time to visit a doctor is a reason for self-medication without prescription", "Pharmacist recommended the antibiotic in the past, hence I use the same drug if a child falls sick", "Friend or relative recommended the antibiotic to give to a child", "I usually give antibiotics to a child because health facility is far from home" and "Child condition got worse when used drugs prescribed by a doctor".

\section{Data Management and Statistical analysis}

The antibiotics knowledge score was calculated as a continuous variable by summarizing the participant's number of correct responses. One point was awarded for each correct response (Yes or No for correct statements), and zero for each wrong or uncertain response, with the maximum correct score of 12 for each respondent was obtained. To describe the general distribution of knowledge, the median score was used as the cutoff to dichotomize this continuous variable for use as the dependent variable for logistic regression. [19]
The knowledge score was categorized into two levels such as poor and good. Descriptive statistics were generated for continuous variables. Logistic regression was carried out to assess the correlation of independent variables (age, sex, education level, income, and occupation) of the caretaker with the main outcome measure (knowledge). Each independent variable was individually regressed with the main outcome measure and crude estimates determined. The variable that was significant at bivariate analysis (set at $\leq 10 \%$ [0.1]) was further selected for the Multivariable regression model. The final analysis in the multivariable model was performed at 95\% confidence level. Data were analyzed using IBM SPSS Statistics for Windows, Version 22.0 (IBM Corp, Armonk, NY, USA).

\section{Ethical approval and consent to participate}

The ethical clearance for the study was granted from the ethical research committee of the Kilimanjaro Christian Medical University College, and permission to conduct the study was sought from the Moshi Municipality Director. Participants (caretakers) were asked to voluntarily take part in the study and were allowed to ask questions to satisfy themselves before agreeing to participate. Each caretaker signed an Informed Consent Form upon acceptance to participate. All participants' data were treated with a high level of confidentiality whereby no unauthorized person was allowed to access any collected data. No names were used on the questionnaires.

\section{Results}

\section{Demographic characteristics of caretakers}

A total of 224 caretakers were included, 108 $(48.2 \%)$ were from KCMC hospital, 79 (35.3\%) from Mawenzi hospital, and 37 (16.5\%) from Longuo dispensary. Most caretakers 214 (95.5\%) were females and only $10(4.5 \%)$ were males. One hundred and eight (48.2\%) had secondary education, $61(27.2 \%)$ attended college, and 55 $(24.6 \%)$ had primary education. The mean age was $29.6 \pm 5.4$, Table 1 . 
Table 1. Caretakers' demographic characteristics $(\mathbf{N}=\mathbf{2 2 4})$

\begin{tabular}{llll}
\hline Variables & & Frequency (n) & Percent (\%) \\
\hline Sex & Female & 214 & 95.5 \\
& Male & 10 & 4.5 \\
\hline Age & 18 to 30 years & 154 & 68.8 \\
& to 40 years & 62 & 27.7 \\
& $>40$ years & 8 & 3.6 \\
\hline Education level & Primary & 55 & 24.6 \\
& Secondary & 108 & 45.2 \\
& College/University & 61 & 27.7 \\
\hline Occupation & Employed & 74 & 33.0 \\
& Businessman/woman & 87 & 38.8 \\
\hline Income per month & (in & 63 & 28.1 \\
\hline Number of children & $<1,000,000$ & 86 & 38.4 \\
& $>1,000,000$ & 138 & 61.6 \\
\hline One & 92 & 41.1 \\
& Two & 97 & 43.3 \\
& Three & 21 & 9.4 \\
& More than three & 14 & 6.3 \\
\hline Facility & Moshi Town & 207 & 92.4 \\
& Outside Moshi Town & 17 & 7.6 \\
\hline & KCMC Hospital & 108 & 48.2 \\
& Mawenzi Hospital & 79 & 35.3 \\
& Longuo Dispensary & 37 & 16.5 \\
\hline
\end{tabular}

*Others: Included students, unemployed, farmers, and livestock keepers 1 TZs is equivalent to 0.00044 USD

\section{Knowledge of antibiotics use}

The majority $(87.9 \%, 197 / 224)$ of all interviewed caretakers had good knowledge and $12.1 \%$ $(27 / 224)$ had poor knowledge. Health care workers played a key role as the source of information on antibiotics and antibiotic use (93.3\%, 209/224).

When assessing the caretaker's knowledge regarding antibiotics, $(95.1 \%, 213 / 224)$ had heard of the following medication: ceftriaxone, penicillin, amoxicillin, and metronidazole, while $(82.6 \%, 185 / 224)$ knew that ceftriaxone, penicillin, amoxicillin, and metronidazole are antibiotics. Few caretakers $(20.5 \%, 46 / 224)$ didn't admit that, if a child presented with a cough, running nose, and a sore throat, and was given antibiotics he/she could be cured more quickly. Nearly half $(48.2 \%, 180 / 224)$ of the respondents, didn't concur that the more expensive the antibiotic is the more effective it will be.
More than half, $(54.9 \%, 123 / 224)$ didn't agree that antibiotic treatments should be withdrawn as soon as the symptoms disappear. The majority $(83.5 \%, 187 / 224)$, knew that inappropriate antibiotic use can cause the risk of antibiotic resistance, while $(82.1 \%, 184 / 224)$ knew that antibiotics should only be obtained with a doctor's prescription. Most participants (93.5\%, 210/224) didn't have the same opinion that antibiotics can be used for any child who presents with fever. More than half $(55.8 \%$, $125 / 224)$, didn't agree that antibiotics can cure an infection caused by a virus. The majority of participants $(75.0 \%, 168 / 224)$ didn't agree that antibiotics and anti-inflammatory/painkillers are the same, while $(98.2 \%, 220 / 224$ were aware that a caretaker should follow the instructions given by the doctor when giving antibiotics to the child, Figure1. 


\section{Caretakers Knowledge regarding antibiotics}

Have you ever heard of this medication;...

Do you think the mentioned above are antibiotics?

If a child presents with cough, running nose, and a...

The more expensive the antibiotic, the more..

Antibiotics should be withdrawn as soon as the...

$48.2 \%$

$20.5 \%$

$82.6 \%$

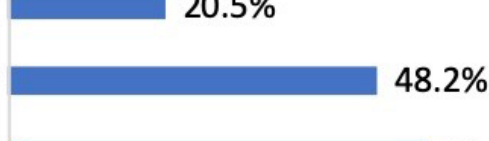

Do you know that inap propriate antibiotic use can... $54.9 \%$

Antibiotics should only be obtained with a doctor...

Antibiotic can be used for any child who present...

Antibiotics can cure infection caused by virus?

Antibiotics and anti-inflammatory/painkillers drugs...

$75.0 \%$

Are you aware that you should follow the..

\section{$\begin{array}{llllll}0.0 \% & 20.0 \% & 40.0 \% & 60.0 \% & 80.0 \% & 100.0 \%\end{array}$}

\section{Figure 1. Knowledge about antibiotic and antibiotic use}

\section{Caretakers' practices with antibiotics}

Caretakers were asked several questions concerning antibiotic use and how they practiced their knowledge. Most caretakers $(75.4 \%, 169 / 224)$, had never requested antibiotics from the doctor when it was not included in the prescription for the illness of their child. The majority of caretakers $(78.1 \%$, $175 / 224)$ informed the doctor if the child was already on another medication for some other illness. Sixty-three percent $(141 / 224)$, did not use the same type of antibiotics as the one they had used in the past if a child presented similar symptoms, while most $(96.4 \%, 216 / 224)$ consulted the doctor if the symptoms were not relieved by self-medicating the children with antibiotics.

Concerning self-medicating a child with antibiotics, most caretakers $(95.1 \%, 213 / 224)$ responded that it was not safe to self-medicate a child with any antibiotics. As to why one decided to self-medicate a child with antibiotics without prescription, (43.8\%, 98/224) responded that the condition of the child did not seem alarming, (38.4\%, 86/224) said they lacked time to visit the doctor, $(37.1 \%, 83 / 224)$ had knowledge of antibiotics for the same symptom, $(28.1 \%, 63 / 224)$ the pharmacist had recommended the same antibiotic in the past, and hence they used the same drug if the child fell sick again, $(20.1 \%$, $45 / 224)$ a friend or relative recommended the antibioticfor the child, while with a few caretakers, $(7.1 \%, 16 / 224)$ an unprescribed antibiotic was given to the child because the health facility was too far from home and $(3.1 \%, 7 / 224)$ indicated that the condition of the child had become worse after they had used the antibiotic prescribed by the doctor, and therefore they decided to selfmedicate the child with yet another antibiotic. Caretakers $(61.6 \%, 138 / 224)$ admitted that it was their usual practice to self-medicate a child with antibiotics. The majority of caretakers (96.9\%, 217/224) checked the expiry date of the medicine before giving it to a child, $28.1 \%$ of whom had had a recommendation from the pharmacist. The majority $(91.5 \%, 205 / 224)$ were aware of the importance of completing the course of antibiotics. 


\section{Caretakers practices regarding antibiotics}

Have you ever requested antibiotics from your...

Do you Inform the doctor if the child is already... $75.4 \%$

Would you reuse an antibiotic which you had...

Do you consult a doctor if the symptoms are not...

Is it safe to self-medicate a child with any...

Child's condition did not seem serious enough... Lack of time to visit a doctor is a reason for self...

I have Knowledge of antibiotics for the same...

Pharmacist recommended the antibiotic in the...

Friend or relative recommended the antibiotic...

Health facility is far from home

Child condition got worse when I used drugs...

Is your usual conduct to self-medicate a child...

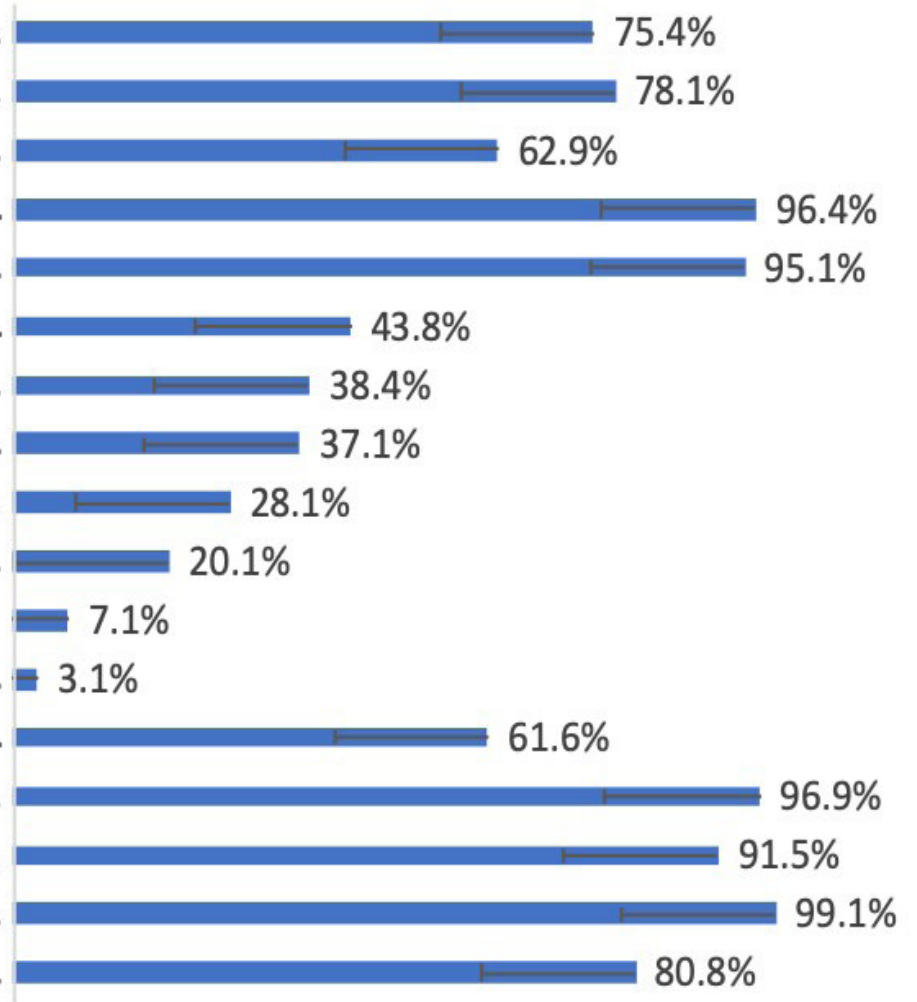

Do you check the expiry date of medicines.. Are you aware about importance of completing...

Are you aware of dose/frequency of...

$80.8 \%$

Are you aware of Adverse Drugs Reactions and...

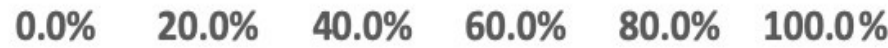

Figure 2. Caretakers practices with antibiotic use and self-medication

Table 2. Factors associated with good knowledge of the uses of antibiotics among caretakers

\begin{tabular}{|c|c|c|c|c|c|}
\hline Variable & & $\begin{array}{l}\text { Crude OR } \\
(95 \% \mathrm{CI}) \\
\end{array}$ & P-value & $\begin{array}{l}\text { Adjusted OR } \\
(95 \% \mathrm{CI})\end{array}$ & P-value \\
\hline \multirow[t]{2}{*}{ Sex } & Female & $0.80(0.09-6.60)$ & 0.6 & & \\
\hline & Male & 1 & & & \\
\hline \multirow[t]{3}{*}{ Age } & 18 to 30 years & $0.95(0.11-8.19)$ & 0.3 & & \\
\hline & 31 to 40 years & $1.33(0.13-12.75)$ & 0.7 & & \\
\hline & $>40$ years & 1 & & & \\
\hline \multirow[t]{3}{*}{ Education level } & Primary & $0.77(0.26-2.28)$ & 0.2 & & \\
\hline & Secondary & $1.78(0.64-4.91)$ & 0.8 & & \\
\hline & College/University & 1 & & & \\
\hline \multirow[t]{3}{*}{ Occupation } & Employed & $7.61(1.61-35.81)$ & 0.01 & $8.43(1.74-40.92)$ & $<0.01$ \\
\hline & Businessman/woman & $1.10(0.46-2.62)$ & 0.1 & $1.20(0.41-2.52)$ & 0.2 \\
\hline & $*$ Others & 1 & & 1 & \\
\hline \multirow{2}{*}{$\begin{array}{l}\text { Income per } \\
\text { month (in TZs) }\end{array}$} & $<1,000,000$ & $1.08(0.45-2.62)$ & & & \\
\hline & $>1,000,000$ & 1 & & & \\
\hline \multirow{4}{*}{$\begin{array}{l}\text { Number of } \\
\text { children }\end{array}$} & One & $1.70(0.06-2.93)$ & 0.6 & $4.19(0.08-6.12)$ & 0.3 \\
\hline & Two & $6.18(1.66-22.92)$ & 0.06 & $7.75(1.89-31.67)$ & 0.01 \\
\hline & Three & $5.27(0.85-32.62)$ & 0.03 & $7.23(1.08-48.51)$ & $<0.01$ \\
\hline & More than three & 1 & & 1 & \\
\hline \multirow[t]{3}{*}{ Facility } & KCMC Hospital & $0.83(0.28-2.45)$ & 0.9 & & \\
\hline & Mawenzi Hospital & $2.31(0.62-8.54)$ & 0.5 & & \\
\hline & Longuo Dispensary & 1 & & & \\
\hline
\end{tabular}


The results of the bivariate and multivariable analyses of the independent association between predictors and knowledge are shown in Table 2 . Only variables that were significant in the bivariate analysis (set to $\mathrm{p} \leq 0.1$ ) were entered in the multivariable analysis.

Being employed (adjusted odds ratio $(\mathrm{aOR})=8.43$, $\mathrm{CI}$ : 1.74-40.92), having two children $(\mathrm{aOR}=7.75, \mathrm{CI}$ : 1.89-31.67) and having three children $(\mathrm{aOR}=7.23$, CI: 1.08-48.51) were significantly associated with good knowledge of antibiotics.

\section{Discussion}

The study aimed at investigating caretakers' knowledge and practices with antibiotics and antibiotic use to their children in the Kilimanjaro region. It is important to quantify the existing knowledge and assess the practices regarding antibiotics and antibiotic use to establish control and mitigation strategies for AMR. Our study is one of the few attempts in assessing the knowledge and practices of caretakers regarding antibiotic and antibiotic use in local settings.

In this study, $87.9 \%$, of all interviewed caretakers had good knowledge, while $12.1 \%$ had poor knowledge of antibiotic and antibiotic use. More than $80 \%$ of the caretakers knew a list of antibiotics provided to them. This is somehow impressive because familiarity with the type of medication is an important step when putting down strategies to control AMR. Participants knew that inappropriate use of any antibiotic could lead to a risk of AMR, allergic and possible side effects. This is was also reported in other studies that AMR can potentially arise from inadequate dosing and discontinuation of the full course of treatment .[20-23] In this study, results showed that caretakers follow the doctors' instructions during antibiotics use for their children. This may be due to the fact that most caretakers were educated and they were likely to know about antibiotics and their effects. This means that good knowledge regarding antibiotics and antibiotic use may lead people to become more conscious of the advantages of using antibiotics appropriately.[24]

Most of the caretakers knew that antibiotics and anti-inflammatory/painkillers are not the same, but few had inappropriate knowledge regarding antibiotics' effectiveness for viral infections. This was also the case in a study conducted in Indonesia. [24] Furthermore, the misunderstanding of antibiotics as potential drugs for viruses, and that antibiotics and painkillers are the same, was also reported in a study done in Cameroon.[25]
Though the familiarity of type of medication exists, still there is confusion about using antibiotics against viral infections, fever, cough in children, running nose, and sore throat. This could have severe implications against the efforts made to fight AMR. Over-the-counter access of antibiotics to the general public due to the non-regulated drugstores and pharmacies in Tanzania and other parts of the world contributes to this challenge.[26] In this study, only two factors were significantly associated with good knowledge regarding antibiotics. Caretakers who were employed and had two or more children had good knowledge, a finding consistent with other studies.[25,27] This could be because they have more time to acquire the necessary information regarding antibiotic use and to seek medical advice more frequently.[27] Participants have reported several reasons for self-medicating children with antibiotics. Lack of time to visit doctors have prior knowledge, pharmacists recommended the same antibiotic in the past, friend or relative recommendation, and distance from health facility have been reported to be the reasons for self-medication a child with antibiotics. Similar observations were made in a study conducted in China.[19]

In Africa, there is extensive use of antibiotics, with over $80 \%$ of antibiotics not being prescribed by doctors, [28] which contributes to the development of AMR. In the Tanzanian setting, inappropriate use of antibiotics has been reported in different populations as shown by the previous findings.[10,29,30] These studies revealed that there are a proportion of individuals with a high level of awareness of the negative consequences of using antibiotics inappropriately including antibiotic resistance, however, they also practice the same.[10,29] Given the current study findings, further studies are advocated particularly in rural areas of Tanzania to ascertain the extent of antibiotic use and misuse.

In Tanzania, several studies have recommended that policy on drug dispensing should be adhered to;[10] and that the government through the Tanzania Medicines and Medical Devices Authority (TMDA) intervene by a mass education, dispensers' education and lawfully enforcing the restriction on access to antibiotics on prescription only policy,[29] engaging in training and education of health care providers in the area of antibiotic prescribing and risk of AMR development.[31] 
In our settings, pharmacies do sell drugs not only to people with antibiotic prescriptions but also to those without prescriptions; here we recommend that pharmacists provide information/ knowledge to people regarding antibiotics, their uses, consequences of consuming them without a doctor's prescription, and also the type of infections that are targeted by such antibiotics. All the recommendations made above are highly emphasized in the current study; moreover, we call upon the use of media campaigns to advocate for the importance of rational use of antibiotics and their effect on human health and the risk of AMR development. This could elevate awareness and will possibly lead to positive change in antibiotic use. A multidisciplinary approach that involves clinicians, pharmacists, nurses, policy-makers, and the general public should be used to discuss the question of antibiotic use and resistance development. Such dialogue should look at the existing policy and underscore the need for policy change on the use of antibiotics and emphasize providing awareness among the general community and health professionals about the positive and negative effects linked to antibiotic use.

\section{Strength and Limitations}

The current study has several strengths and limitations that should be acknowledged. The study has reported some interesting findings on caretakers' knowledge and practice regarding antibiotic use in children. The study adds to the available evidence regarding knowledge on antibiotic use among caretakers. These findings relied mainly on the caretaker's honesty and ability to recall, which may have reduced objectivity of the study. Likewise, this study was conducted in only three health facilities, hence the results may not be representative of the situation in the entire population of Kilimanjaro.

\section{Conclusion}

This study has revealed that caretakers in Moshi have good knowledge of antibiotic use. However, despite the good knowledge, malpractice in the use of antibiotics in under five years old children was reported. For that reason, in addition to the already provided recommendations from other studies done in this area, we call upon the use of media campaigns to advocate for the importance of rational use of antibiotics and its effect on human health and the risk of AMR development.

\section{Authors Contributions}

BJP conceived the idea, designed the study, participated in data collection, and performed the data analysis and interpretation.

SIM conceived the idea, designed the study, participated in data collection, and performed the data analysis and interpretation.

DCK conceived the idea, designed the study, participated in data collection, and performed the data analysis and interpretation.

RRB participated in drafting and critical review of the manuscript.

NIY participated in drafting and critical review of the manuscript.

PGH performed data analysis and interpretation AK contributed to the drafting of the manuscript and critical review of the manuscript.

\section{Conflict of interest}

All authors declared that there is no conflict of interest.

This article is published open access under the Creative Commons Attribution-NonCommercial NoDerivatives (CC BYNC-ND4.0). People can copy and redistribute the article only for noncommercial purposes and as long as they give appropriate credit to the authors. They cannot distribute any modified material obtained by remixing, transforming or building upon this article. See https:// creativecommons.org/licenses/by-nc-nd/4.0/

\section{Reference}

1. Parimi N, Pinto Pereira LM, Prabhakar P. Caregivers' practices, knowledge and beliefs of antibiotics in paediatric upper respiratorytract infections in Trinidad and Tobago: A crosssectional study. BMC Fam. Pract. 2004;5:1-8.

2. Simonsen GS, Tapsall JW, Allegranzi B, Talbot EA, Lazzari S. The antimicrobial resistance containment and surveillance approach - A public health tool. Bull. World Health Organ. 2004;82:928-34.

3. Prestinaci F, Pezzotti P, Pantosti A. Antimicrobial resistance: A global multifaceted phenomenon. Pathog. Glob. Health [Internet]. Taylor \& Francis; 2015;109:309-18. Available from: http://dx.doi.org/10.1179/204777321 5Y.0000000030

4. Binali D, Musaya J, Lampiao F. Determinants of antimicrobial use in diarrhoea management among under-five children in Zomba .Malawi. J. Microbiol. Antimicrob. 2018;11:22-30.

5. Rogawski ET, Westreich DJ, Becker-Dreps S, Adair LS, Sandler RS, Sarkar R, et al. Antibiotic treatment of diarrhoea is associated with decreased time to the next diarrhoea episode among young children in Vellore, India. Int. J. Epidemiol. 2015;44:978-87. 
6. Hamre HJ, Glockmann A, Schwarz R, Riley $\mathrm{DS}$, Baars EW, Kiene $\mathrm{H}$, et al. Antibiotic Use in Children with Acute Respiratory or Ear Infections: Prospective Observational Comparison of Anthroposophic and Conventional Treatment under Routine Primary Care Conditions. Evidence-Based Complement. Altern. Med. 2014;2014:1-17.

7. WHO. WHO Global Strategy for Containment of Antimicrobial Strategy for Containment of Antimicrobial Resistance [Internet]. World Heal. Organ. 2001 [cited 2020 Mar 20]. Available from: https://www.who.int/drugresistance/ WHO_Global_Strategy_English.pdf?ua=1

8. WHO. Global action plan on antimicrobial resistance [Internet]. WHO. 2015 [cited 2020 Jun 20]. p. 1-28. Available from: http://www. who.int/drugresistance/global_action_plan/ en/

9. Hemo B, Shamir-Shtein NH, Silverman BG, Tsamir J, Heymann AD, Tsehori S, et al. Can a nationwide media campaign affect antibiotic use? Am. J. Manag. Care. 2009;15:529-34.

10. Mbwambo G, Emidi B, Mgabo M, Sigalla G, Kajeguka D. Community knowledge and attitudes on antibiotic use in Moshi Urban, Northern Tanzania: Findings from a cross sectional study. African J. Microbiol. Res. 2017;11:1018-26.

11. Quizhpe PA, Gassowski M, Encalada T L, Barten F. Differences in antibiotic use and knowledge between adolescent and adult mothers in Ecuador. F1000Research. 2013;2:1-10.

12. Salama RA, N.Bader K, Rahman AS, Hashmi FY. Parents 'knowledge, attitude and practice of antibiotic use for upper respiratory tract infections in children in the United Arab Emirates. Epidemiol. Biostat. Public Heal. 2018;15:1-9.

13. Salonga MJC. Beliefs and Practices of Parents on the use of antibiotics for their children with upper respiratory tract infection. Pediatr. Infect. Dis. Soc. Phillipines. 2009;1:1-6.

14. Zyoud SH, Taha AA, Araj KF, Abahri IA, Sawalha AF, Sweileh WM, et al. Parental knowledge, attitudes and practices regarding antibiotic use for acute upper respiratory tract infections in children: A cross-sectional study in Palestine. BMC Pediatr. BMC Pediatrics; 2015;15:1-9.

15. Ilankathir S, Kameshvell C, Balamurugan K. Drug Therapy in Upper Respiratory Tract Infections in Paediatric Patients and Parental Attitude : A Survey in a Multicenter Hospital. 2015;3:1217-9.

16. Awad I., Aboud E. Knowledge, Attitude and Practice towards Antibiotic Use among the Public in Kuwait. PLoS One. 2015;10:1-15.
17. Simba D, Kakoko D, Semali I, Kessy A, Embrey M. Household Knowledge of Antimicrobials and Antimicrobial Resistance in the Wake of an Accredited Drug Dispensing Outlet ( ADDO ) Program Rollout in Tanzania. PLoS One. 2016;11:1-13.

18. Ding L, Sun Q, Sun W, Du Y, Li Y, Bian X, et al. Antibiotic use in rural China : a crosssectional survey of knowledge, attitudes and self-reported practices among caregivers in Shandong province. BMC Infect. Dis. BMC Infectious Diseases; 2015;1-9.

19. Yu M, Zhao G, Lundborg CS, Zhu Y, Zhao Q, $\mathrm{Xu} \mathrm{B}$. Knowledge, attitudes, and practices of parents in rural China on the use of antibiotics in children: a cross-sectional study. $B M C$ Infect. Dis. 2014;1-8.

20. Erku DA, Mekuria AB, Belachew SA. Inappropriate use of antibiotics among communities of Gondar town, Ethiopia: A threat to the development of antimicrobial resistance. Antimicrob. Resist. Infect. Control. BioMed Central Ltd.; 2017;6.

21. Kardas P, Devine S, Golembesky A, Roberts C. A systematic review and meta-analysis of misuse of antibiotic therapies in the community. Int. $J$. Antimicrob. Agents. 2005;26:106-13.

22. Ayukekbong JA, Ntemgwa M, Atabe AN. The threat of antimicrobial resistance in developing countries: Causes and control strategies. Antimicrob. Resist. Infect. Control. Antimicrobial Resistance \& Infection Control; 2017;6:1-8.

23. Dache A, Dona A, Ejeso A. Inappropriate use of antibiotics, its reasons and contributing factors among communities of Yirgalem town, Sidama regional state, Ethiopia: A crosssectional study. SAGE Open Med. 2021;9:1-9.

24. Widayati A, Suryawati S, de Crespigny C, Hiller JE. Knowledge and beliefs about antibiotics among people in Yogyakarta City Indonesia: A cross sectional population-based survey. Antimicrob. Resist. Infect. Control. 2012;1:17.

25. Ekambi GAE, Ebongue CO, Penda C, Nga EN, Mpondo EM, Moukokoid CEE. Knowledge, practices and attitudes on antibiotics use in Cameroon: Self-medication and prescription survey among children, adolescents and adults in private pharmacies. PLoS One. 2019;14:117.

26. Waseem H, Ali J, Sarwar F, Khan A, Rehman HSU, Choudri M, et al. Assessment of knowledge and attitude trends towards antimicrobial resistance (AMR) among the community members, pharmacists/pharmacy owners and physicians in district Sialkot, Pakistan. Antimicrob. Resist. Infect. Control. Antimicrobial Resistance \& Infection Control; 2019;8:1-7. 
27.A1-Saleh S, Abu Hammour K, Abu Hammour W. Influencing factors of knowledge, attitude, and practice regarding antibiotic use in children with upper respiratory tract infections in Dubai. J. Eval. Clin. Pract. 2020;26:197-202.

28. Kimang'a AN. A situational analysis of antimicrobial drug resistance in Africa : are we losing the battle? Ethiop J Heal. Sci. 2012;2:135-43.

29. Horumpende PG, Said SH, Mazuguni FS, Antony ML, Kumburu HH, Sonda TB, et al. Prevalence, determinants and knowledge of antibacterial self-medication: A cross sectional study in North-eastern Tanzania. PLoS One. 2018;13:1-13.
30. Kajeguka DC, Moses EA. Self-medication practices and predictors for self-medication with antibiotics and antimalarials among community in Mbeyacity, Tanzania. Tanzan. J. Health Res. 2017;19:1-10.

31. Lyimo S, Geoffrey S, Emidi B, Mgabo MR, Kajeguka DC. Cross-sectional Survey on Antibiotic Prescription Practices Among Health Care Providers in Rombo District, Northern Tanzania. East African Heal. Res. J. 2018;2:1-8. 